\title{
Relationship between vertical jump performance during different training periods and results of $200 \mathrm{~m}$-sprint
}

Authors' Contribution: A Study Design B Data Collection C Statistical Analysis D Data Interpretation E Manuscript Preparation F Literature Search G Funds Collection

\author{
Pawel Siembida ${ }^{1 \text { AB }}$, Magdalena Zawadka2 CDEF, Piotr Gawda2 AD \\ ${ }^{1}$ Interdisciplinary Scientific Group of Sports Medicine, Department of Sports Medicine, \\ Medical University of Lublin, Lublin, Poland \\ 2 Department of Sports Medicine, Faculty of Health Sciences, \\ Medical University of Lublin, Lublin, Poland
}

abstract

Background: The purpose of the current study was to investigate: (1) differences between three types of countermovement jumps (CMJ), (2) development of lower-body strength during training periods, and (3) relationship between $200 \mathrm{~m}$ personal best results and jumping ability in sprinters.

Material and methods: A total of 14 male sprinters from a local university academic sport club participated in the study. Athletes performed three variants of CMJ: with arm swing (AS), without AS, and from a maximal squat position. We took measurements twice: during the active rest period and the final phase of the preparatory period. The Optojump photoelectric cell system was used for measurements. Statistical significance was set at $p \leq 0.05$.

Results: The effect of the training period and the jump variant was shown on all jump parameters (height, total energy, and specific energy; $p<0.001$ ). Personal best $200 \mathrm{~m}$ time was significantly correlated only with total energy in both training periods in all jump variants.

Conclusions: According to the results obtained in this study, we conclude that: (1) jumping parameters depend on CM] variants, (2) jumping abilities improved during sprinter training, (3) 200m-sprint PB are related with total energy, but not with specific energy and jump height.

Key words: biomechanics; physical performance; countermovement jump; sprint; jumping ability.

\section{article details}

Article statistics: Word count: 2,366; Tables: 3; Figures: 1; References: 31

Received: January 2021; Accepted: June 2021; Published: September 2021

Full-text PDF: http://www.balticsportscience.com

Copyright @ Gdansk University of Physical Education and Sport, Poland

Indexation: Celdes, Clarivate Analytics Emerging Sources Citation Index (ESCI), CNKI Scholar (China National Knowledge Infrastructure), CNPIEC, DOAJ, EBSCO - Central \& Eastern European Academic Source, EBSCO - SPORTDiscus, EBSCO Discovery Service, Google Scholar, Index Copernicus, J-Gate, Naviga (Softweco, Primo Central (ExLibris), ProQuest - Family Health, ProQuest - Health \& Medical Complete, ProQuest - Illustrata: Health Sciences, ProQuest Nursing \& Allied Health Source, Summon (Serials Solutions/ProQuest, TDOne (TDNet), Ulrich's Periodicals Directory/ ulrichsweb, WorldCat (OCLC)

Funding: This research received no specific grant from any funding agency in the public, commercial, or not-for-profit sectors.

Conflict of interests: Corresponding author:

Open Access License: Authors have declared that no competing interest exists.

Magdalena Zawadka, Department of Sports Medicine, Faculty of Health Sciences, Medical University of Lublin; Chodźki 7, 20-093 Lublin, Poland; magdalenazawdka91@gmail.com

This is an open access article distributed under the terms of the Creative Commons Attribution-Non-Commercial-NoDerivatives 4.0 International (https://creativecommons.org/licenses/by-nc-nd/4.0/), which permits use, distribution, and reproduction in any medium, provided the original work is properly cited, the use is non-commercial and is otherwise in compliance with the license. 


\section{INTRODUCTION}

Jump performance has been suggested as a useful tool for power assessment in athletes [1, 2]. Squat jump (SJ) and countermovement jump (CMJ) are commonly used tests to measure jumping ability [3-5]. SJ is used as a measure of lower-body concentric strength/power, while $\mathrm{CMJ}$ as a measure of lower-body reactive strength/power [6]. Both types of vertical jumps are valid and relevant measurement tools of lower-body force and power ability [7]. Moreover, CMJ performance is influenced by the combined effects of eccentric and concentric muscle contractions in the ankle, knee and hip, called the stretch-shortening cycle, as well as by whether or not the arms are swung in the takeoff phase [2]. Pérez-Castilla et al. revealed that the countermovement depth may also affect several CMJ performance variables [8].

Several previous studies have revealed that vertical jumping ability and other motor skills can be related. A relationship between zigzag agility and the ball and jumping performance has been found in soccer players [9]. Running performance in the 800-m race was investigated in the context of a relationship between strength and jumping abilities [10]. CMJ and SJ power generating capabilities have been shown to be strongly related to sprint performance over $10 \mathrm{~m}$ from a block start. Previous studies of Loturco et al. showed that correlations of SJ and CMJ with actual 100-m sprinting times amounted to -0.82 and -0.85 , respectively. Because of practicality, safety, and a correlation of these tests with the actual times obtained by top-level athletes in 100-m dash events, authors gave their recommendation for regularly incorporating SJ and CMJ into elite sprint-testing routines [11, 12]. Thus, an ability to generate power both elastically during a CMJ and concentrically during a SJ should be considered as good indicators of predicting sprint performance [13]. Increases in lower-body strength positively translate into sprint performance [14]. The results of a study by Comfort et al. illustrate the importance of developing lower-body strength to enhance sprint and jump performance [15]. However, there is limited knowledge and very little research into the relationship between $200 \mathrm{~m}$ sprint results and jumping ability during different training periods. A training plan is divided into training periods, which fulfil a key function in the traditional theory of training periodization: generalized and preliminary work (general and specific preparatory periods), event-specific work and competitions (competition period). In addition, a third period (transition period) is set aside for active recovery and rehabilitation $[16,17]$. Moreover, CMJ can be performed in many ways, e.g. with or without arm swing (AS), with a different depth of the countermovement squatting position. The importance of these CMJ variants as predictors of sport performance has not been well established so far.

Thus, the purpose of current study was to investigate: (1) differences between three types of jumps, (2) development of lower-body strength during training periods (active rest and specific preparation period) (3) relationship between $200 \mathrm{~m}$ personal best (PB) results and jumping ability in sprinters. It was hypothesized that sprint and jump performance will be related. It was further hypothesized that parameters of jumps variants will be different and results of jumping performance will improve during the training season.

\section{MATERIAL AND METHODS}

\section{Participants}

A total of 14 male sprinters from a local university academic sport club participated in the study. At the time of testing, the subjects reported no injury that would prevent their participation in physical activity for more than 2 weeks during the previous 6 months. Informed consent was obtained from each subject. Table 1 demonstrates anthropometric characteristic of the participants before the first measurement. The study was approved by the Ethical Committee at the Medical University of Lublin and conducted according to the Declaration of Helsinki. 


\begin{tabular}{lcccc} 
& $\bar{x}$ & SD & Min. & Max. \\
\hline Age [years] & 20.43 & 3.46 & 17.00 & 29.00 \\
Training experience [years] & 5.21 & 2.83 & 1.00 & 11.00 \\
Body mass [kg] & 70.43 & 8.81 & 55.00 & 83.00 \\
Body length [cm] & 179.93 & 5.89 & 172.00 & 189.00 \\
BMI [kg/m ${ }^{2}$ ] & 21.69 & 1.86 & 18.59 & 25.06 \\
Personal best result 200m [s] & 22.95 & 1.25 & 21.46 & 24.79 \\
\hline
\end{tabular}

\section{Design and Procedures}

The participants performed their warm-up which consisted, according to Whelan et al. recommendation, of a $3 \mathrm{~min}$ jog followed by sprint-specific dynamic exercises of the lower limbs $[18,19]$. The total warm-up time was 15 minutes. After the warm-up and prior to testing, three variation of the CMJ were demonstrated to the participants. The participants were instructed to jump naturally and as high as they could, performing all jumps with maximal effort. Prior to testing, participants were required to practice CMJ with preferred depth (with and without AS). After that, they were instructed to perform a maximal countermovement (greater than self-preferred depth and greater than "parallel squat"). The knee flexion was not defined in any trial, but it was greater in CMJ from maximal squat than in CMJs from self-preferred depth.

The CMJ without arm swing (AS) was performed with both hands on the waist, while performing a downward movement until preferred knee flexion followed by a vertical jump of maximum effort. The CMJ with AS was performed similarly to the previous jump but with arm movement. The CMJ from the maximal squat position was performed with both hands on the waist during downward movement until the maximal knee flexion (greater than "parallel squat") and followed by a vertical jump.

The participants were required to perform 3 trials of each jump in random order separated by 10 s rest between trials and 2 min rest between sets [19]. The best trial of each jump variant was recorded and further statistically analyzed.

Measurements were taken twice. The first measurement was taken in November 2018 during an active rest period, and the second measurements was taken in May 2019 during the final phase of a specific preparatory period. The period of active rest lasted from the 2018 outdoor competition season to the next preparatory period. It consisted of rest, recovery and recreational activity which did not include resistance training. The specific preparatory period consisted of high-intensity training, speed, plyometric and resistance exercises. Workouts were individually planned based on the results from the last season of each athlete.

For jump measurements, an Optojump photoelectric cells system (Microgate, Bolzano, Italy) was used. The device consists of two parallel bars connected to a computer. One bar acts as a transmitter unit containing light emitting diodes positioned $0.003 \mathrm{~m}$ above the ground and the second bar acts as a receiver unit. The Optojump was demonstrated in previous studies as a valid and reliable tool for monitoring jumping performance [20].

Three parameters of jump performance were analyzed in this study: jump height, total energy and specific energy. Total energy means the total energy expressed by the athlete during the test (Specific Energy x Athlete Weight). Specific energy [J/kg] is energy produced during the test calculated with the following formula: 


$$
\sum h \text { jumps } \times g(1)
$$

Where $h$ is a jump height and $g$ is gravitational acceleration.

Sprinters' personal best (PB) 200m times until 2020 were obtained from a database of the National Athletics Association and included only results with allowed wind conditions $(\leq 2 \mathrm{~m} / \mathrm{s})$.

\section{Statistical Analysis}

The normal distribution of the data was verified with the Shapiro-Wilk test. Jumping parameters were analyzed using repeated measures analysis of variance (ANOVA) in model 3 (jumps variants) $\mathrm{x} 2$ (training period). The significant results were analyzed further using post hoc Tukey HSD test. The partial Eta square $\left(\eta p^{2}\right)$ was used for effect size assessment. Pearson's coefficient ( $r$ ) was u sed to calculate the c orrelations b etween the jump parameters and $200 \mathrm{~m}$ personal best results. The magnitude of correlation was assessed with the following thresholds: $<0.1$, trivial; $<0.1-0.3$, small; $<0.3-0.5$, moderate; $<0.5-0.7$, large; $<0.7-0.9$, very large; and $<0.9-1.0$, almost perfect [21]. Statistical significance was set at $\mathrm{p} \leq 0.05$. Data analysis was conducted using the Statistica software (ver. 13.1). The data are presented as means with standard deviations (SD).

\section{RESULTS}

A repeated measures ANOVA revealed statistically significant main effect of the training period and the jump variant on all jump parameters (height, total energy and specific energy). Mean jump height was greater in the preparatory period than in the active rest period $\left(\mathrm{F}(1,13)=41.30 ; \mathrm{p}<0.001 ; \eta \mathrm{p}^{2}=0.76\right)$ and it was the greatest in CMJ with AS $\left(\mathrm{F}(1,13)=58.26 ; \mathrm{p}<0.001 ; \eta \mathrm{p}^{2}=0.82\right)$ comparing with two other jumps variants. Table 2 . shows means and SD of the jumps parameters.

Table 2. Means and standard deviations (SD) of the measured parameters

\begin{tabular}{lcccccc} 
& \multicolumn{2}{c}{ CM] with AS } & \multicolumn{2}{c}{ CMJ without AS } & \multicolumn{2}{c}{ CMJ max squat } \\
& Mean & SD & Mean & SD & Mean & SD \\
\hline Active rest period & & & & & & \\
Jump height [cm] & 54.98 & 5.77 & 45.39 & 4.95 & 52.34 & 4.96 \\
Total energy [J] & 380.64 & 67.68 & 313.59 & 56.13 & 363.00 & 65.54 \\
Specific energy [J/kg] & 5.39 & 0.57 & 4.45 & 0.49 & 5.13 & 0.49 \\
\hline The end of the preparatory period & & & & & & 6.15 \\
Jump height [cm] & 58.21 & 6.25 & 47.79 & 4.72 & 54.42 & 68.49 \\
Total energy [J] & 398.85 & 69.72 & 327.31 & 54.00 & 373.20 & 0.60 \\
Specific energy [J/kg] & 5.71 & 0.61 & 4.69 & 0.46 & 5.34 & 0.49 \\
\hline
\end{tabular}

Mean total energy was greater in the preparatory period than in the active rest period $\left(\mathrm{F}(1,13)=42.13 ; \mathrm{p}<.001 ; \eta \mathrm{p}^{2}=0.76\right)$ and, it was the greatest in $\mathrm{CMJ}$ with $\mathrm{AS}(\mathrm{F}(1,13)=56.70$; $\left.\mathrm{p}<.001 ; \eta \mathrm{p}^{2}=0.81\right)$ comparing with the two other jumps.

Mean specific energy was greater in the preparatory period than in the active rest period $\left(\mathrm{F}(1,13)=41.68 ; \mathrm{p}<.001 ; \eta \mathrm{p}^{2}=0.76\right)$, and it was the greatest in $\mathrm{CMJ}$ with $\mathrm{AS}(\mathrm{F}(1,13)=58.59$; $\left.\mathrm{p}<.001 ; \eta \mathrm{p}^{2}=0.82\right)$ comparing with the two other jumps variants. The interactions of the period and jump variant were not statistically significant. Table 3 shows the results of ANOVA. 
Table 3. ANOVA results for main effects (training period; jump variant) and interaction (period $\mathrm{x}$ jump). Values in bold stand for statistical significance $(\mathrm{p}<0.05)$

\begin{tabular}{|c|c|c|c|c|}
\hline & $\mathrm{F}$ & $\mathrm{p}$ & $\mathrm{Eta}^{2}$ partial & Post hoc \\
\hline \multicolumn{5}{|l|}{ Jump height } \\
\hline Training period & 41.30 & $<0.001$ & 0.76 & \multirow{3}{*}{$\begin{array}{c}\text { All comparisons } \\
\text { significant } p<0.01\end{array}$} \\
\hline Jump variant & 58.26 & $<0.001$ & 0.82 & \\
\hline period $x$ jump & 1.20 & 0.32 & 0.08 & \\
\hline \multicolumn{5}{|l|}{ Total energy } \\
\hline Training period & 42.13 & $<0.001$ & 0.76 & \multirow{3}{*}{$\begin{array}{c}\text { All comparisons } \\
\text { significant } p<0.01\end{array}$} \\
\hline Jump variant & 56.70 & $<0.001$ & 0.81 & \\
\hline period x jump & 1.02 & 0.36 & 0.07 & \\
\hline \multicolumn{5}{|l|}{ Specific energy } \\
\hline Training period & 41.68 & $<0.001$ & 0.76 & \multirow{3}{*}{$\begin{array}{c}\text { All comparisons } \\
\text { significant } p<0.01\end{array}$} \\
\hline Jump variant & 58.59 & $<0.001$ & 0.82 & \\
\hline period $x$ jump & 1.21 & 0.31 & 0.09 & \\
\hline
\end{tabular}

Personal best $200 \mathrm{~m}$ time was significantly correlated only with total energy in both training periods in all jump variants. In the active rest period, the strongest negative correlation $(r=-0.67 ; p=0.008)$ with $200 \mathrm{~m}$ time was observed in total energy of CMJ from the maximal squat position. In the preparatory period, correlation analysis showed a very strong negative relationship $(\mathrm{r}=-0.71 ; \mathrm{p}=0.005)$ between total energy of CMJ without AS and 200 PB results. Table 4 and Figure 1 show Pearson correlation results.

Table 4. Pearson correlation of jump parameters and 200m PB results. Values in bold stand for statistical significance $(\mathrm{p}<0.05)$

\begin{tabular}{|c|c|c|c|c|c|}
\hline & & $r(X . Y)$ & $r^{2}$ & $\mathrm{t}$ & $\mathrm{p}$ \\
\hline \multicolumn{6}{|c|}{ Active rest period } \\
\hline & Jump height & -0.24 & 0.06 & -0.86 & 0.41 \\
\hline \multirow[t]{3}{*}{ CMJ with AS } & Total energy & -0.61 & 0.37 & -2.66 & 0.02 \\
\hline & Specific energy & -0.24 & 0.06 & -0.87 & 0.40 \\
\hline & Jump height & -0.31 & 0.10 & -1.13 & 0.28 \\
\hline \multirow[t]{3}{*}{ CMJ without AS } & Total energy & -0.64 & 0.41 & -2.88 & 0.01 \\
\hline & Specific energy & -0.31 & 0.10 & -1.12 & 0.28 \\
\hline & Jump height & -0.40 & 0.16 & -1.52 & 0.15 \\
\hline \multirow[t]{2}{*}{ CMJ max squat } & Total energy & -0.67 & 0.45 & -3.16 & 0.008 \\
\hline & & -0.40 & 0.16 & -1.52 & 0.15 \\
\hline \multicolumn{6}{|c|}{ Preparatory period } \\
\hline & Jump height & -0.24 & 0.06 & -0.84 & 0.41 \\
\hline \multirow[t]{3}{*}{ CMJ with AS } & Total energy & -0.59 & 0.35 & -2.51 & 0.03 \\
\hline & Specific energy & -0.24 & 0.06 & -0.86 & 0.41 \\
\hline & Jump height & -0.39 & 0.15 & -1.45 & 0.17 \\
\hline \multirow[t]{3}{*}{ CMJ without AS } & Total energy & -0.71 & 0.50 & -3.45 & 0.005 \\
\hline & Specific energy & -0.39 & 0.15 & -1.47 & 0.17 \\
\hline & Jump height & -0.35 & 0.12 & -1.30 & 0.23 \\
\hline \multirow[t]{2}{*}{$\mathrm{CMJ}$ max squat } & Total energy & -0.64 & 0.41 & -2.90 & 0.01 \\
\hline & Specific energy & -0.35 & 0.12 & -1.30 & 0.22 \\
\hline
\end{tabular}



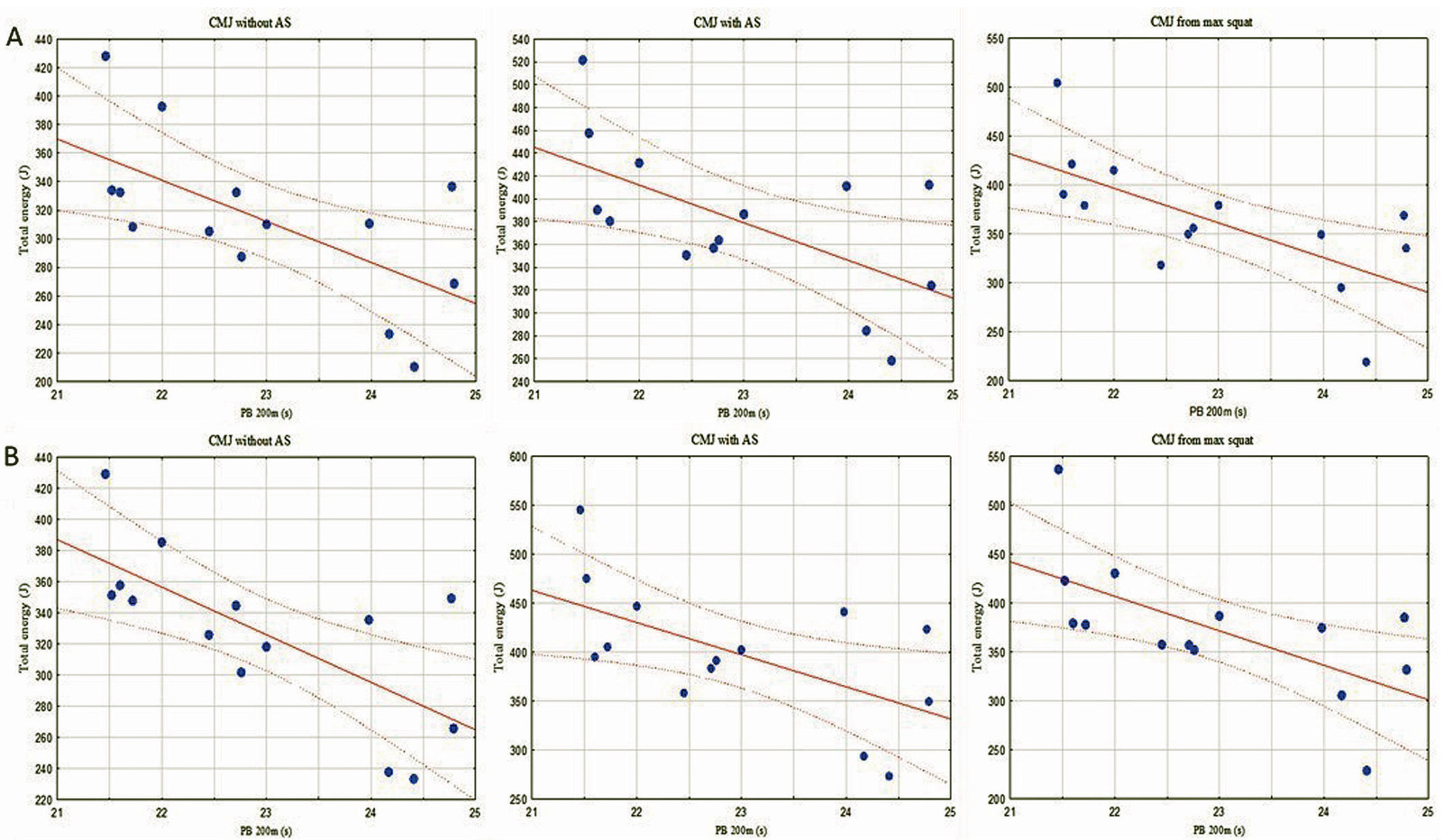

Fig. 1. Scatter plots with trend lines and $95 \% \mathrm{Cls}$ (confidence intervals) show correlation between total energy and PB $200 \mathrm{~m}$ during the active rest period (A) and the preparatory period (B)

\section{DISCUSSION}

In line with our hypothesis, this study found a relationship between $200 \mathrm{~m}$ sprint and jump performance, but only in total energy, not in jump height and specific energy. Height, total and specific energies during CMJ with AS were greater than during the two other CMJ variants. Jump performance improved during the preparatory period in comparison to active rest, as it was expected.

Both specific and total energy are calculated based on jump height. However, 200m PB was correlated only with total energy, which is calculated by multiplying specific energy and athletes' weight. We believe that athletes' greater body mass is related with greater musculature and, in result, with a greater strength. Thus, greater strength associated with body mass can explain why greater total energy is related with sprint performance. Previously, Maćkała et al. reported that $200 \mathrm{~m}$ performance was related to body mass $(\mathrm{r}=-0.80)$ but weakly related to horizontal jumping ability [22]. Maximal strength has been shown to determine sprint performance in high level soccer players [23]. For example, Comfort et al. demonstrated that relative and absolute strength are related with $20 \mathrm{~m}$ sprint, but absolute strength shows the strongest relationship with 5-m sprint and jumping abilities [15]. This author's finding was unexpected due to the fact that body mass has to be accelerated during activities and, therefore, measuring relative strength seemed to better predict performance during sprinting and jumping. Contrary to a previous study by Bachero-Mena et al. [10], who found relationship between jump height and middle distance running, we did not find a relationship between $200 \mathrm{~m}$ performance and jumps height. Wisløff et al. reported a correlation between vertical jumping performance and sprint times $(30 \mathrm{~m})$ as both were derivatives of maximal strength [23]. Results of our study are not consistent with previous observation, probably due to the different distance used in our investigation. Summarizing, as our study demonstrated, grater body mass related with increased muscle mass and strength can be considered as a better predictor of $200 \mathrm{~m}$-sprint performance than jump height. 
In the active rest period, the strongest negative correlation $(r=-0.67 ; p=0.008)$ with $200 \mathrm{~m}$ time was observed in total energy of CMJ from the maximal squat position. In the preparatory period, a very strong negative relationship $(r=-0.71 ; p=0.005)$ was found between total energy of CMJ without AS and 200 PB results. CMJ without AS isolates lower extremity force production and eliminates potential arm-swing variation [24]. Our study results revealed the strongest relationship between $200 \mathrm{~m}$ PB results and total energy of CMJ without AS (from a self-selected or larger depth). It may suggest that arm swing can increase jump height, but as a $200 \mathrm{~m}$-sprint predictor CMJ without AS is probably more adequate.

CMJ with AS in our study contributed to greater height and energy than CMJ without AS and CMJ from maximal squat. Previously, SJ and CMJ had been compared to investigate differences between concentric power and elastic power generated during stretch shortening cycle [25]. CMJ with and without AS were compared as well demonstrating that AS improved the CMJ by increasing the jump height relative to jumping without an AS. The AS significantly shortened the braking phase and prolonged the accelerating phase $[2,26]$.

To the best of the authors' knowledge, this is the first study to compare three CMJ variants - with and without AS and with different squat depth during countermovement. Results of the current study indicate that jump height is the greatest with AS and when participants squat to a preferred depth. Comparing CMJs without AS, increased squatting depth gives some advantage in jumping height, probably due to higher velocities of the center of mass than during the self-selected jumps [27]. These results corroborate with results of previous investigations that demonstrated a direct relationship between squat depth and CMJ performance [28]. However, other previous studies indicate that larger countermovement depths were not associated with greater jump height comparing to selfpreferred CMJ depth [8]. Findings of the current study can be explained primarily in terms of changes in muscle length resulting from modulations of joint angles achieved in this study. Kinematic parameters and knee flexion, in particular, can by strong determinants of jumping performance $[29,30]$. For recommendations, these results can be concluded as follows: AS improves CMJ height comparing with CMJs without AS; a deeper squat position during CMJ without AS improves jump height comparing with a self-selected squatting position.

Jumping performance has significantly improved during training. The greatest average improvement in jump height was observed during CMJ with AS $(3.23 \mathrm{~cm})$ in comparison with CMJ without AS $(2.40 \mathrm{~cm})$ and CMJ from maximal squat $(2.08 \mathrm{~cm})$. Our findings are consistent with previous studies [31].

Our study has some limitations. The main limitation is the large dispersion of participants' age (17-29 years old), and as a result, substantial differences in training experience (1-11 years). Thus, further investigations should verified our findings in a more homogeneous group.

\section{CONCLUSION}

According to the results obtained in this study, we conclude that: (1) jumping parameter depends on CMJ variants (2) jumping abilities improve during sprinter training, (3) $200 \mathrm{~m}$-sprint $\mathrm{PB}$ are related with total energy, but not with specific energy and jump height. 


\section{REFERENCES}

[1] McGuigan MR, Doyle TLA, Newton M, Edwards DJ, Nimphius S, Newton RU. Eccentric utilization ratio: effect of sport and phase of training. J Strength Cond Res. 2006 Nov;20(4):992-5. https://doi.org/10.1519/00124278-20061100000042

[2] Vaverka F, Jandačka D, Zahradník D, et al. Effect of an arm swing on countermovement vertical jump performance in elite volleyball players. J Hum Kinet. 2016 Oct 14;53:41-50. https://doi.org/10.1515/hukin-2016-0009

[3] Janicijevic D, Knezevic OM, Mirkov DM, et al. The force-velocity relationship obtained during the squat jump exercise is meaningfully influenced by the initial knee angle. Sport Biomech. 2020 Mar 30;1-10. https://doi.org/10.1080/14 763141.2020 .1727559

[4] Kochanowicz A, Niespodziński B, Mieszkowski J, Kochanowicz K, Zasada M. Vertical jump peak power estimation in young male gymnasts. Balt J Health Phys Activ. 2016 Mar 31;8(1):25-31. https://doi.org/10.29359/BJHPA.08.1.03

[5] Oh D-S, Choi Y-H, Shim Y-J, Park S-H, Lee M-M. Concurrent validity, inter-, and intrarater reliabilities of smart device based application for measuring vertical jump performance. Balt J Health Phys Activ. 2020 Sep 30;12(3):35-46. https://doi.org/10.29359/BJHPA.12.3.04

[6] Pagaduan J, J. Schoenfeld B, Pojskic H. Systematic review and meta-analysis on the effect of contrast training on vertical jump performance. Strength Cond J. 2019 Jun;41(3):63-78. https://doi.org/10.1519/SSC.0000000000000442

[7] Riggs MP, Sheppard JM. The relative importance of strength and power qualities to vertical jump height of elite beach volleyball players during the counter-movement and squat jump. JHSE. 2009;4(3):221-36. https://doi.org/10.4100/ jhse.2009.43.04

[8] Pérez-Castilla A, Rojas FJ, Gómez-Martínez F, García-Ramos A. Vertical jump performance is affected by the velocity and depth of the countermovement. Sport Biomech. 2019 Jul 30;0(0):1-16. https://doi.org/10.1080/14763141.201 9.1641545

[9] Köklü Y, Alemdaroğlu U, Özkan A, Koz M, Ersöz G. The relationship between sprint ability, agility and vertical jump performance in young soccer players. Science \& Sports. 2015 Feb 1;30(1):e1-5. https://doi.org/10.1016/j. scispo.2013.04.006

[10] Bachero-Mena B, Pareja-Blanco F, Rodríguez-Rosell D, Yáñez-García JM, Mora-Custodio R, González-Badillo JJ. Relationships between sprint, jumping and strength abilities, and $800 \mathrm{~m}$ performance in male athletes of national and international levels. J Hum Kinet. 2017 Sep;58:187-95. https://doi.org/10.1515/hukin-2017-0076

[11] Loturco I, Pereira LA, Cal Abad CC, et al. Vertical and horizontal jump tests are strongly associated with competitive performance in 100-m dash events. J Strength Cond Res. 2015 Jul;29(7):1966-71. https://doi.org/10.1519/ JSC.0000000000000849

[12] Loturco I, Kobal R, Maldonado T, et al. Jump Squat is more related to sprinting and jumping abilities than olympic push press. Int J Sports Med. 2017 Jul;38(8):604-12. https://doi.org/10.1055/s-0035-1565201

[13] Maulder PS, Bradshaw EJ, Keogh J. Jump kinetic determinants of sprint acceleration performance from starting blocks in male sprinters. J Sports Sci Med. 2006 Jun 1;5(2):359-66.

[14] Seitz LB, Reyes A, Tran TT, Saez de Villarreal E, Haff GG. Increases in lower-body strength transfer positively to sprint performance: A systematic review with meta-analysis. Sport Med. 2014 Dec;44(12):1693-702. https://doi org/10.1007/s40279-014-0227-1

[15] Comfort P, Stewart A, Bloom L, Clarkson B. Relationships between strength, sprint, and jump performance in well-trained youth soccer players. J Strength Cond Res. 2014 Jan;28(1):173-7. https://doi.org/10.1519/JSC.0b013e318291b8c7

[16] Issurin VB. New horizons for the methodology and physiology of training periodization. Sport Med. 2010 Mar 1;40(3):189-206. https://doi.org/10.2165/11319770-000000000-00000

[17] Haugen T, Seiler S, Sandbakk Ø, Tønnessen E. The training and development of elite sprint performance: an integration of scientific and best practice literature. Sports Medicine - Open. 2019 Nov 21;5(1):44. https://doi.org/10.1186/ s40798-019-0221-0

[18] Whelan N, O’Regan C, Harrison AJ. Resisted sprints do not acutely enhance sprinting performance. J Strength Cond Res. 2014 Jul;28(7):1858-66. https://doi.org/10.1519/JSC.0000000000000357

[19] Gindre C, Lussiana T, Hebert-Losier K, Mourot L. Aerial and terrestrial patterns: A novel approach to analyzing human running. Int J Sports Med. 2016 Jan;37(1):25-9. https://doi.org/10.1055/s-0035-1555931

[20] Healy R, Kenny IC, Harrison AJ. Assessing reactive strength measures in jumping and hopping using the OptojumpTM System. J Hum Kinet. 2016 Dec 1;54:23-32. https://doi.org/10.1515/hukin-2016-0032

[21] Hopkins WG, Marshall SW, Batterham AM, Hanin J. Progressive statistics for studies in sports medicine and exercise science. Med Sci Sports Exerc. 2009 Jan;41(1):3-13. https://doi.org/10.1249/MSS.0b013e31818cb278

[22] Maćkala K, Michalski R, Čoh M, Rausavljević N. The relationship between 200 m performance and selected anthropometric variables and motor abilities in male sprinters. Coll Antropol. 2015 Jul;39 Suppl 1:69-76.

[23] Wisløff U, Castagna C, Helgerud J, Jones R, Hoff J. Strong correlation of maximal squat strength with sprint performance and vertical jump height in elite soccer players. Br J Sport Med. 2004 Jun 1;38(3):285-8. https://doi.org/10.1136/ bjsm.2002.002071

[24] Heishman AD, Daub BD, Miller RM, Freitas EDS, Frantz BA, Bemben MG. Countermovement jump reliability performed with and without an arm swing in ncaa division 1 intercollegiate basketball players. J Strength Cond Res 2020 Feb;34(2):546-58. https://doi.org/10.1519/JSC.0000000000002812

[25] Van Hooren B, Zolotarjova J. The difference between countermovement and squat jump performances: a review of underlying mechanisms with practical applications. J Strength Cond Res. 2017 Jul;31(7):2011-20. https://doi org/10.1519/JSC.0000000000001913

[26] Lees A, Vanrenterghem J, De Clercq D. Understanding how an arm swing enhances performance in the vertical jump. J Biomech. 2004 Dec;37(12):1929-40. https://doi.org/10.1016/j.jbiomech.2004.02.021

[27] Sánchez-Sixto A, Harrison AJ, Floría P. Larger Countermovement increases the jump height of countermovement jump. Sports (Basel). 2018 Oct 26;6(4). https://doi.org/10.3390/sports6040131 
[28] Gheller RG, Dal Pupo J, Lima LAP de, et al. Effect of squat depth on performance and biomechanical parameters of countermovement vertical jump. Revista Brasileira de Cineantropometria \&amp; Desempenho Humano. 2014 Sep;16(6):658-68. https://doi.org/10.5007/1980-0037.2014v16n6p658

[29] McErlain-Naylor S, King M, Pain MTG. Determinants of countermovement jump performance: A kinetic and kinematic analysis. J Sport Sci. 2014 Nov 26;32(19):1805-12. https://doi.org/10.1080/02640414.2014.924055

[30] Moran KA, Wallace ES. Eccentric loading and range of knee joint motion effects on performance enhancement in vertical jumping. Human Mov Sci. 2007 Dec 1;26(6):824-40. https://doi.org/10.1016/j.humov.2007.05.001

[31] Tønnessen E, Shalfawi SA, Haugen T, Enoksen E. The effect of 40-m repeated sprint training on maximum sprinting speed, repeated sprint speed endurance, vertical jump, and aerobic capacity in young elite male soccer players. J Strength Cond Res. 2011 Sep;25(9):2364-70. https://doi.org/10.1519/JSC.0b013e3182023a65 